\title{
Mir-21 Regulation of MARCKS Protein and Mucin Secretion in Airway Epithelial Cells
}

\author{
W. Randall Lampe ${ }^{1,2}$, Shijing Fang ${ }^{1}$, Qi Yin ${ }^{1}$, Anne L. Crews ${ }^{1}$, \\ Joungjoa Park ${ }^{1}$, Kenneth B. Adler, \\ ${ }^{1}$ Molecular Biomedical Sciences, North Carolina State University, Raleigh, USA \\ ${ }^{2}$ Environmental and Molecular Toxicology, North Carolina State University, Raleigh, USA \\ Email: kbadler@ncsu.edu
}

Received February 1, 2013; revised March 3, 2013; accepted March 10, 2013

Copyright (C) 2013 W. Randall Lampe et al. This is an open access article distributed under the Creative Commons Attribution License, which permits unrestricted use, distribution, and reproduction in any medium, provided the original work is properly cited.

\begin{abstract}
Hypersecretion of mucus characterizes many inflammatory airway diseases, including asthma, chronic bronchitis, and cystic fibrosis. Excess mucus causes airway obstruction, reduces pulmonary function, and can lead to increased morbidity and mortality. MicroRNAs are small non-coding pieces of RNA which regulate other genes by binding to a complementary sequence in the target mRNA. The microRNA miR-21 is upregulated in many inflammatory conditions and, interestingly, miR-21 has been shown to target the mRNA of Myristoylated Alanine-Rich C Kinase Substrate (MARCKS), a protein that is an important regulator of airway mucin (the solid component of mucus) secretion. In these studies, we determined that exposure of primary, well-differentiated, normal human bronchial epithelial (NHBE) cells to the pro-inflammatory stimulus lipopolysaccharide (LPS) increased expression of both miR-21 and MARCKS in a time-dependent manner. To investigate whether miR-21 regulation of MARCKS played a role in mucin secretion, two separate airway epithelial cell lines, HBE1 (papilloma virus transformed) and NCI-H292 (mucodepidermoid derived) were utilized, since manipulation of miR-21 is performed via transfection of commercially-available miR-21 inhibitors and mimics/activators. Treatment of HBE1 cells with LPS caused concentration-dependent increases in expression of both miR-21 and MARCKS mRNA and protein. The miR-21 inhibitor effectively reduced levels of miR-21 in the cells, coincident with an increase in MARCKS mRNA expression over time as well as enhanced mucin secretion, while the miR-21 mimic/activator increased levels of miR-21, which coincided with a decrease in expression of MARCKS and a decrease in mucin secretion. These results suggest that miR-21 is increased in airway epithelial cells following exposure to LPS, and that miR-21 downregulates expression of MARCKS, which may decrease mucin secretion by the cells. Thus, miR-21 may act as a negative feedback regulator of mucin secretion in airway epithelial cells, and may do so, at least in part, by downregulating expression of MARCKS.
\end{abstract}

Keywords: MicroRNA-21; MARCKS; Airway; Epithelial; Inflammation; Mucus

\section{Introduction}

Hypersecretion of mucus characterizes many inflammatory airway diseases including asthma, chronic bronchitis, and cystic fibrosis. Excessive mucus can obstruct airways, inhibit respiration, increase susceptibility to infection, and lead to increased morbidity and mortality. Mucus is a gel made up of water and mucins (large complex glycoproteins) that are post-translationally modified by myristoylation, glycosylation and/or phosphorylation. Mucins provide mucus with its viscosity and elasticity [1]. At least 20 different mucins have been discovered in humans, 11 of which have been identified in the lungs. MUC5AC and MUC5B are the most prominent types in the airways [2].

Myristoylated alanine-rich C-kinase substrate (MARCKS) protein is a ubiquitous Protein Kinase C (PKC) substrate that has been shown to play an important role in regulation of mucin secretion by airway epithelium in vitro [3-5] and in vivo [6,7]. The evolutionarily-conserved N-terminal region of MARCKS [6] is clearly involved in this action, as peptides analogous to the MARCKS N-terminus attenuate mucin secretion in airway epithelial cells both in vitro [3] and in vivo [6].

MicroRNAs are small non-coding pieces of RNA typically about 22 bases long. They regulate other genes binding to a complementary sequence in the 3 '-untranslated region of the target mRNA. MicroRNAs serve an 
important regulatory role in proliferation [8], differentiation [9], development, migration [10] angiogenesis [11], apoptosis [12,13] and carcinogenesis [9]. The micro RNA miR-21 has been shown to target many tumor suppressors and it is upregulated in many types of cancers and in various inflammatory conditions [14-19]. Interestingly, miR-21 has been shown to specifically target the mRNA of MARCKS [20].

Given these associations, we investigated whether or not miR-21 could be involved in mucin secretion by airway epithelial cells in response to the proinflammatory stimulus, LPS, and, if so, whether miR-21 regulation of MARCKS could be part of the mechanism. The results indicate that: 1) Treatment of well-differentiated primary normal human bronchial epithelial (NHBE) cells with LPS derived from $E$. coli provoked time-dependent increases in expression of both miR-21 and MARCKS; 2) LPS treatment caused a similar increase in expression of both miR-21 and MARCKS in the virally-transformed HBE1 human airway epithelial cell line; 3) Inhibition of miR-21 via transfection of a miR-21 inhibitor after LPS treatment increased expression of MARCKS coincident with an increase in mucin secretion in another human airway epithelial cell line, NCI-H292 cells (derived from a mucoepidermoid carcinoma); 4) Activation of miR-21 via transfection of a mimic/inhibitor decreased expression of MARCKS and decreased LPS-provoked mucin secretion in these cells; and 5) Inhibition of MARCKS protein with a peptide identical to the MARCKS N-terminus inhibited mucin secretion in these cells regardless of treatment. Thus, it appears that miR-21 may play an important role as a negative feedback regulator of MARCKS expression and mucin secretion following inflammatory stimulation in airway epithelial cells.

\section{Materials and Methods}

\subsection{Cell Culture}

Well-differentiated NHBE cells from two separate donors were utilized for the initial studies. NHBE cells were purchased from Lonza corporation (Walkersville, $\mathrm{MD})$, and grown and maintained in air/liquid interface as described previously [21] until, after approximately 18 days in culture, a well-differentiated epithelium was formed. After initial experiments indicated that expression of both miR-21 and MARCKS were enhanced by exposure of cells to lipopolysaccharide (LPS) from E. coli (Figures 1 and 2), studies to determine if there was a connection between miR-21 and MARCKS expression were performed using both a commercially-available inhibitor and an activator/mimic of miR-21 (described below) that required use of cells with a high transfection efficiency, so a human bronchial epithelial cell line, papilloma virus-transformed HBE1 cells [22]; a generous gift from Dr. Reen Wu, University of California, Davis,
CA) were used. HBE1 cells were cultured as previously described [23]. In additional studies examining the effects of these reagents on airway mucin secretion, a second cell line, NCI-H292 cells (derived from a human pulmonary mucoepidemoid carcinoma; purchased from the American Type Culture Collection [ATCC, Manassas, VA) were chosen, as these cells have been used previously to study mucin production [24]. RPMI $1640+10 \%$ FBS with penicillin/streptomycin and amphotericin added was the medium used and cells were maintained in a humidified air $/ 5 \% \mathrm{CO}_{2}$ environment until they reached $\sim 70 \%$ confluence before they were transfected with the

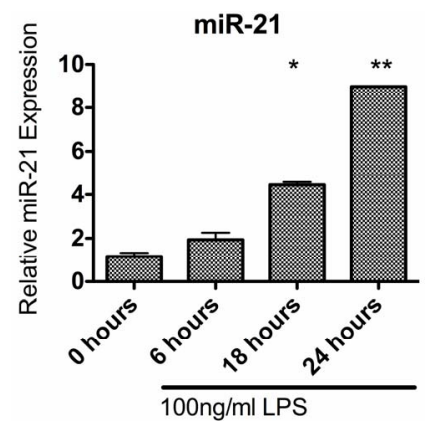

(a)

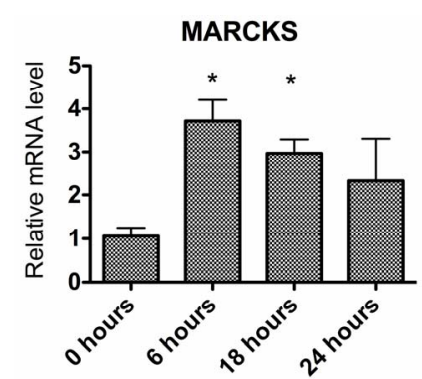

(b)

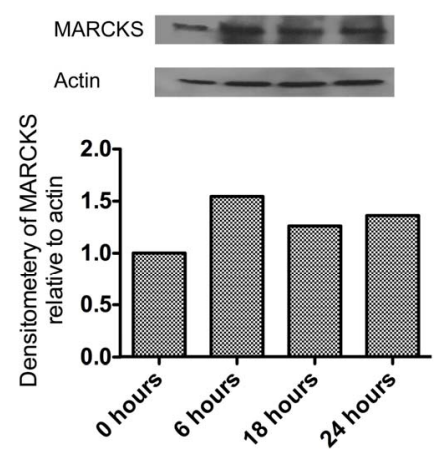

(c)

Figure 1. Exposure of well-differentiated NHBE cells to LPS (100 $\mathrm{ng} / \mathrm{ml})$ increases expression of: (a) miR-21 expression over time, from 0 - 24 hrs; $(*=\mathbf{p}<0.005 * *=\mathbf{p}<$ 0.0005 using Student's T-test, $n=4$ ); (b) mRNA levels of MARCKS, which peak at 6 hrs and gradually decline over the next $18 \mathrm{hrs}$; $(*=\mathrm{p}<0.005, \mathrm{n}=4)$ and (c) Protein expression of MARCKS, which mimics the mRNA response by peaking at $6 \mathrm{hrs}$ and then plateauing or decreasing slightly from 6 - 24 hours. 
miR-21 inhibitor or mimic. Forty-eight hrs post transfection, cells were exposed to a range of concentrations of LPS and responses related to miR-21 and MARCKS expression and function monitored, as described below.

\subsection{MiR-21 Inhibitor and miR-21 Mimic}

To alter miR-21 levels in these cells, we utilized both an

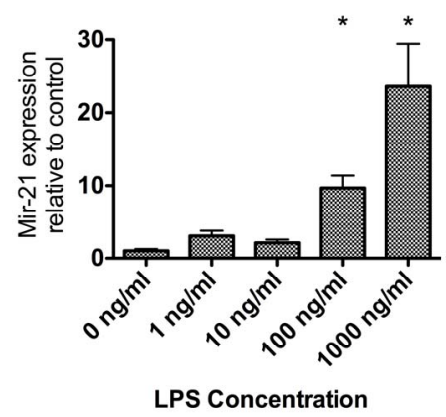

(a)

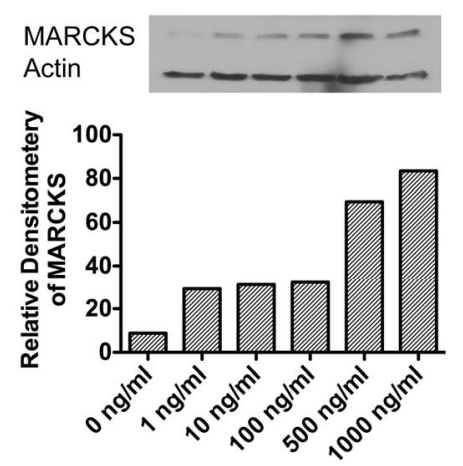

(b)

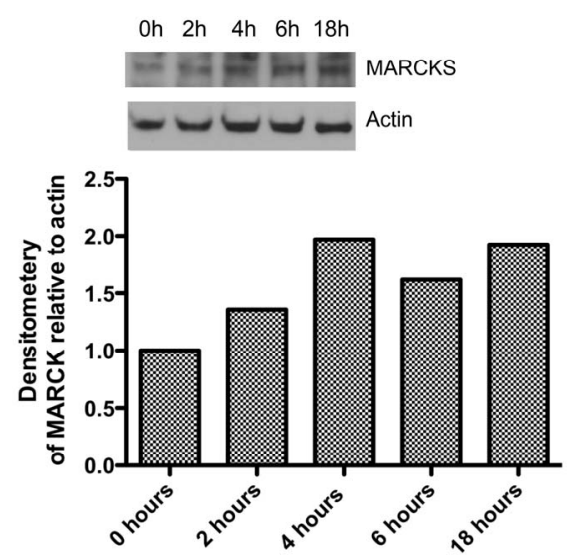

(c)

Figure 2. (a) Expression of miR-21 in HBE1 cells is increased in a concentration-dependent manner after exposure to LPS for 6 hrs, with significant increases between 100 and $1000 \mathrm{ng} / \mathrm{ml}$. (*= $\mathbf{p}<0.05$, using Student's t-test, $\mathbf{n}=3$ ); (b) Protein expression of MARCKS also is increased at 500 and $1000 \mathrm{ng} / \mathrm{ml}$ LPS; (c) Protein expression of MARCKS increases at 4 hrs post LPS (500 $\mathrm{ng} / \mathrm{ml})$ exposure and plateaus thereafter, similar to what is observed in NHBE cells illustrated in Figure 1.
anti-miR-21 inhibitor and a pre-miR-21 activator, both purchased from Ambion (Forster City, CA). MicroRNA inhibitors are small, chemically modified single-stranded RNA molecules designed to specifically bind to and inhibit endogenous miRNA molecules and enable miRNA functional analysis by down-regulation of miRNA activity and endogenous miRNA function after transfection into cells. For these studies, we utilized the mirVana ${ }^{\circledR}$ miRNA inhibitor containing the hsa-miR-21-5p sequence:

UAGCUUAUCAGACUGAUGUUGA. In contrast, miRNA mimics are small, chemically modified doublestranded RNAs that mimic endogenous miRNAs and enable miRNA functional analysis by up-regulation of miRNA activity. Here, we utilized the mirVana ${ }^{\circledR}$ miRNA mimic (also from Ambion) containing the stem loop sequence:

GUCGGGUACAUCGACUGAUGUUGACUGUUGAA UCUCAUGGCAACACCAGUCGAUGGGCUGUCUGA CA. Effective use of these reagents in other cell types has been described previously [25].

\subsection{Transfections}

Here, we utilized the mirVana ${ }^{\circledR}$ miRNA mimic (also from Ambion) containing the stem loop HBE1 and NCIH292 cells were grown, submerged in medium, in plastic wells to approximately $70 \%$ confluence, and at that point transfected with either the miR-21 inhibitor or activator. Transfections were performed using Qiagen (Roche, Indianapolis, IN) "HiPerFect" transfection reagent, a unique blend of cationic and neutral lipids suited to both lowand high-throughput transfection of miRNA mimics or inhibitors, according to the manufacturer's protocol. Forty-eight hours later, cells were exposed to either a range of concentrations of LPS or control media, and appropriate experiments performed.

\subsection{Analysis of mRNA Expression via RT-PCR}

NHBE cells were treated with $100 \mathrm{ng} / \mathrm{ml}$ of LPS for various time periods. Cells were harvested and RNA was extracted with an RNeasy kit (Qiagen). For miRNA analysis, real-time qPCR was carried out on a iQ5 Detection System (Bio-Rad) using 5 ng RNA input, $2 \times$ iQ SYBR Green Supermix (Bio-Rad). For the detection 50 ng RNA input, $2 \times$ iQ SYBR Green Supermix, and 5 pmol gene-specific primer pairs were used. Thermal cycling conditions were $95^{\circ} \mathrm{C}$ for 3 minutes, 40 cycles at $95^{\circ} \mathrm{C}$ for 10 seconds, and $55^{\circ} \mathrm{C}$ for 30 seconds, followed by melting curve analyses. RNA input was normalized to endogenous controls: beta-actin or $36 \mathrm{~B} 4$. The $2^{-\Delta \Delta \mathrm{ct}}$ method was used to calculate the fold relationships in miRNA expression among the tested samples. 


\subsection{Analysis of Protein Expression via Western Blot}

Westerns blots were used to evaluate levels of MARCKS within the cells after exposure to LPS or control media. After the predetermined time interval, cells were lysed and protein was extracted in buffer containing Complete Mini Protease inhibitor (Roche), washed with cold PBS and scraped into lysis buffer $[50 \mathrm{mmol} / \mathrm{L}$ Tris- $\mathrm{Cl}(\mathrm{pH}$ 7.6), $1 \mathrm{mmol} / \mathrm{L}$ ethylenediamine tetraacetic acid, 100 $\mathrm{mmol} / \mathrm{L} \mathrm{NaCl}, 100 \mathrm{mmol} / \mathrm{L} \mathrm{MgCl}, 1 \mathrm{mmol} / \mathrm{L}$ phenylmethylsulfonyl fluoride, $1 \mathrm{mmol} / \mathrm{L}$ dithiothreitol, $1 \%$ $(\mathrm{v} / \mathrm{v})$ protease inhibitor cocktail, and phosphatase inhibitor cocktail (Sigma, St. Louis, MO)]. Western blots used a primary antibody against MARCKS (Upstate, Lake Placid, NY) followed by biotinylated goat anti-mouse secondary (both from Abcam, Cambridge, MA) and then Streptavidin HRP (Santa Cruz, Santa Cruz, CA). Blots were developed with Supersignal (Thermo, Waltham Massachusetts) and normalized to $\beta$-actin (Santa Cruz) using Adobe ${ }^{\circledR}$ Photoshop ${ }^{\circledR}$ CS3.

\subsection{Measurements of Mucin Secretion via ELISA}

Mucin was collected and assayed as described previously [3]. Briefly, after the treatment period, medium was collected and the content of secreted mucin (measured as the major respiratory mucin, MUC5AC) quantified via a sandwich enzyme-linked immunosorbent assay using an antibody to MUC5AC (Neomarkers, Freemont, CA) as the capture antibody with the reporter antibody being a 17Q2 pan-mucin antibody [26,23]. The 17Q2 antibody was purified from murine acites fluid (Covance, Gaithersburg $\mathrm{MD}$ ) and further purified using an ImmunoPure(G) IgG purification kit (Pierce Biotechnology, Rockford, IL) following the manufacturer's protocol and then conjugated with alkaline phosphatase (EMD Biosciences). The ELISA Substrate was 4-nitrohenyl phosphate (Sigma, Saint Louis, MO).

\subsection{Statistical Analysis}

Graphpad Prism ${ }^{\circledR}$ software was used to perform unpaired two-tailed Student's T-test as indicated in the figure legends.

\section{Results}

\subsection{Exposure to LPS Enhances Expression of Both miR-21 and MARCKS in Human Airway Epithelium}

As illustrated in Figure 1(a), exposure of NHBE cells to LPS $(100 \mathrm{ng} / \mathrm{ml})$ results in increased expression of miR21 in a time - dependent manner. Both mRNA and protein expression of MARCKS also was enhanced by ex- posure to LPS at the six-hour time point, but plateaued or decreased after this time, coinciding with an increase in miR-21 expression (Figures 1(b) and (c)). Both miR-21 and MARCKS expression were enhanced similarly in HBE1 cells after exposure to LPS for 6 hrs (Figure 2).

\subsection{Transfection of the $\operatorname{mirVana}^{\circledR}$ miR-21 Inhibitor Reduces Expression of miR-21 in HBE1 Cells; This Correlates with Enhanced Expression of MARCKS}

Transfection of the mirVana $^{\circledR}$ miR-21 (200 nM) inhibitor into HBE1 cells for $48 \mathrm{hrs}$ effectively reduced expression levels of miR-21. This correlated with an increase in expression of MARCKS mRNA (Figure 3).

\subsection{Transfection of the mirVana Pre-miR-21 Activator into HBE1 Cells Increases Expression of miR-21; This Correlates with Decreased Expression of MARCKS}

Transfecting HBE1 with $200 \mathrm{nM}$ of the pre-miR-21 activator increases levels of miR-21 in the cells, correlating

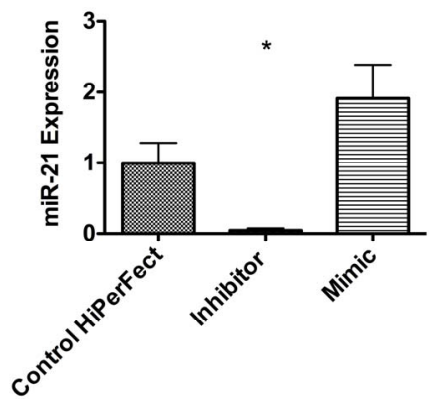

(a)

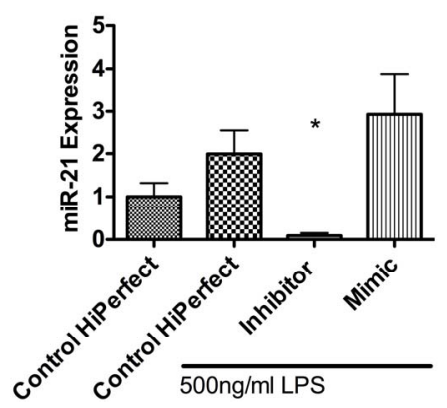

(b)

Figure 3. Transfection of the mirVana ${ }^{\circledR}$ miR-21 inhibitor $(200 \mathrm{nM})$ or the mirVana $^{\circledR}$ pre-miR-21 mimic (200 $\left.\mathrm{nM}\right)$ into HBE1 cells for 48 hrs shows a decrease in expression of miR-21 with the inhibitor and an increase in expression of miR-21 with the mimic 3 (a). When these cells were treated with $500 \mathrm{ng} / \mathrm{ml}$ of LPS for $6 \mathrm{hrs,} \mathrm{(b),} \mathrm{miR-21} \mathrm{expression}$ increased in control cells treated with the HiPerFect transfection reagent, while expression was inhibited with the mirVana $^{\circledR}$ miR-21 inhibitor (200 $\left.\mathrm{nM}\right)$ and enhanced with the mirVana $^{\circledR}$ pre-miR-21 mimic $(200 \mathrm{nM}) .\left(^{*}=\mathbf{p}<0.05\right.$ using Student's T-test, $\mathbf{n}=3$ ). 
with decreased expression of MARCKS RNA (Figure 4).

\subsection{Mucin Secretion by NCI-H292 Cells Is Affected by the miR-21 Inhibitor and Mimic, and Further by Peptides Targeting MARCKS Protein}

As illustrated in Figure 5, LPS (100ng/ml) increased mucin secretion by NCI-H292 cells after $30 \mathrm{~min}$ exposure. Pretreatment of the cells with the mirVana ${ }^{\circledR}$ miR-21 inhibitor resulted in higher levels of secreted mucin in response to LPS than cells exposed to the HiPerfect transfection reagent used as a control, while pretreatment with the mirVana ${ }^{\circledR}$ pre-miR activator decreased mucin secretion in response to LPS compared to cells without the activator. Additional pretreatment of the cells for 30 min with $50 \mu \mathrm{M}$ of the MANS peptide, a reagent that inhibits function of MARCKS in airway epithelial cells $[3,6]$, further attenuated the mucin secretory response, implicating MARCKS in the secretory pathway, as de-

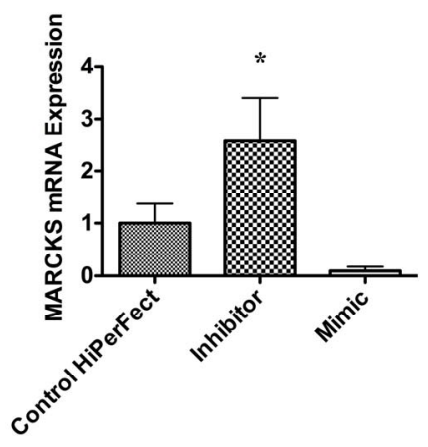

(a)

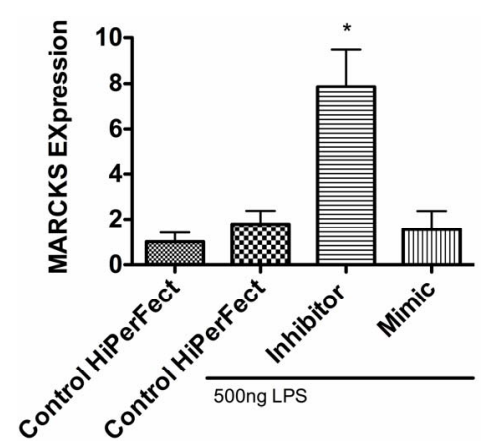

(b)

Figure 4. (a) Transfection of the mirVana ${ }^{\circledR}$ miR-21 inhibitor $(200 \mathrm{nM})$ or the mirVana $^{\circledR}$ pre-miR-21 mimic (200 nM) into HBE1 cells for 48 hrs, followed by examination via RT-PCR of MARCKS mRNA expression in these cells, shows that treatment with the inhibitor increases mRNA expression of MARCKS, while treatment with the mimic decreases it; (b) When these cells were treated with $500 \mathrm{ng} / \mathrm{ml}$ of LPS for 6 hrs, mRNA expression of MARCKS was enhanced in cells transfected with the inhibitor and slightly decreased in cells treated with the mimic. $\left(^{*}=\mathbf{p}<0.05\right.$ using Student's T-test, $\mathbf{n}=3)$.

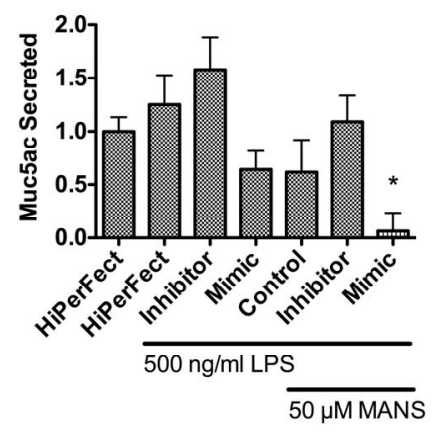

Figure 5. Effects of miR-21 inhibitor and mimic, and of a MARCKS-inhibitory peptide (MANS) on secretion of mucin (MUC5AC) by NCI-H292 cells exposed to $500 \mathrm{ng} / \mathrm{ml}$ LPS. NCI-H292 cells were transfected with the mirVana ${ }^{\circledR}$ miR-21 inhibitor or with the mirVana ${ }^{\circledR}$ pre-miR-21 mimic, both at $200 \mathrm{nM}$, for $48 \mathrm{hrs}$, then treated with LPS for 30 min and mucin secretion measured by ELISA as described. Transfection with the inhibitor increased secretion, while transfection with the mimic decreased secretion. Preincubation of cells for $30 \mathrm{~min}$ with $50 \mu \mathrm{M}$ of the MANS peptide, which inhibits function of MARCKS protein, attenuated secretion in cells whether they were exposed to the HiPerfect $^{\circledR}$ transfection reagent only, to the miR-21 inhibitor, or to the miR-21 mimic/activator, implicating MARCKS in the secretory response. Cells transfected with the miR-21 mimic secrete significantly less mucus when treated with MANS peptide. $(*=p<0.001$ using Student's T-test) Values are means $\pm S E, n=6$ at each point.

scribed previously [27]

\section{Discussion}

MicroRNAs are fairly short (21 - 25 nucleotides in length) strands of non-coding RNA. They serve an important regulatory role in proliferation [8], differentiation [9], development and migration [10], angiogenesis [11], apoptosis [12] and carcinogenesis [14]. In humans and other mammals, miRNAs bind to the 3' untranslated region of their target gene, forming an imperfect complement. This serves to act as a repressor of translation.

Human miR-21, mapped at chromosome 17q23.2, and present within the protein-coding gene VMP1 (or TMEM49) is one of the most extensively studied microRNAs, as it has been associated with both cancer and inflammation. MiR-21 targets many tumor suppressor genes, such as PTEN, PDCD4, Tropomyosin, TGFBRII, RhoB, Bcl2, IL-12 and CDK2AP1 [28,29], and has been shown to stimulate invasion, intravasation, and metastasis [14].

MiR-21 also has been associated with inflammation. It inhibits the TGF- $\beta$ signaling pathway, which is known to inhibit adipogenesis and stimulate inflammation $[29,30]$. It has been shown to specifically target TGF-beta 1 and 2 and TGF beta receptors [15]. Upregulation of miR-21 causes cell proliferation, while downregulation allows cell to stop dividing and/or undergo apoptosis. MiR-21 is a 
trigger for fibroblast dysfunction and fibrosis and is upregulated in cardiac infarctions [18]. It is also upregulated in individuals with idiopathic pulmonary fibrosis, and in lungs of mice with bleomycin-induced fibrosis. A possible target for miR-21 in fibrosis is Smad7, an inhibitory Smad, which is an important regulator of TGF- $\beta$. MiR-21 prevents Smad7 from being made, which stops TGF- $\beta$ from being inhibited. This allows Smad 3 to become activated, increasing collagenase activity and ultimately leading to increased deposition of collagen in the lung parenchyma [30].

Interestingly, miR-21 recently has been shown to also directly target MARCKS protein, binding to MARCKS in the 3' untranslated region from the nt713-734, a region of MARCKS highly conserved among species. Since in previous studies from this laboratory, MARCKS has been shown to be an important regulatory molecule in the process of airway mucin secretion as well as inflammation $[3,6,31]$, we looked here at a possible connection between airway inflammation, mucin secretion, MARCKS and miR-21.

In studies using primary well-differentiated normal human bronchial epithelial cells cultured at an air/liquid interface, and using exposure to LPS as a model of inflammation, we found that, indeed, LPS exposure increased of miR-21. Coincident with that increase, expression of MARCKS protein also was enhanced by LPS, but MARCKS expression plateaued after approximately 6 hours of exposure, while miR-21 expression continued to increase. This suggested that miR-21 might be downregulating expression of MARCKS in these cells, which could have a downstream effect of attenuating mucin secretion since MARCKS is integral to the mucin secretory pathway. Thus, we performed additional studies utilizing a commercially-available miR-21 inhibitor as well as a miR-21 activator. Since these studies required efficient transfection of these reagents into cells, we switched the model system from primary NHBE cells to the papilloma virus - transformed HBE1 cell line, as described previously [23].

LPS exposure had the same effect on HBE1 cells, increasing expression of both miR-21 and MARCKS. Treatment with the miR-21 inhibitor decreased significantly levels of miR-21 in the cells with or without exposure to LPS, and this coincided with an increase in expression of MARCKS at the mRNA and protein levels. In contrast, treatment of HBE1 cells with the miR-21 mimic resulted in downregulation of expression of MARCKS under baseline conditions and after exposure of the cells to LPS. Thus, it appears from these findings that miR-21 may act as a negative regulator of MARCKS expression in airway epithelial cells, similar to its role as a negative regulator of MARCKS in prostate cancer cells [20]. One could speculate that miR-21 functions as part of a negative-feedback mechanism that buffers cellular responses to inflammatory stimuli.

Since MARCKS has been shown to be integral to the mucin secretory process, we then examined how expression of miR-21 and subsequent regulation of MARCKS expression could affect mucin secretion. We turned to a second cell line for these studies, the NCI-H292 cell line, derived from a human epidermoid tumor, since these cells are excellent models for airway mucin secretion, especially of MUC5AC, the predominant human airway mucin $[1,2,23]$. The results of the secretion studies supported the potential anti-inflammatory role of miR-21 in airway epithelium, as treatment with the miR-21 inhibitor, which increases MARCKS expression, also provoked secretion of mucin by cells treated with LPS, while treatment with the miR-21 mimic, which downregulates MARCKS expression, resulted in decreased mucin secretion. To ascertain that indeed MARCKS was functionally associated with the secretory responses, pretreatment of the cells with the MANS peptide, a reagent that is identical to the evolutionarily-conserved N-terminus of MARCKS and which has been shown to inhibit mucin secretion and other functions of MARCKS [3,6,31-34], reduced secretion in cells treated with the either the control HiPerFect transfection reagent, cells transfected with the miR-21 inhibitor, or cells treated with the miR-21 mimic/activator.

In summary, it appears that inflammatory stimulation of airway epithelial cells, in this case by exposure to LPS, provokes enhanced expression of the microRNA, miR-21. MiR-21 then appears to target MARCKS mRNA, decreasing levels of MARCKS protein in these cells, and via this mechanism apparently also decreases the mucin secretory response to LPS. These results, while limited to in vitro studies, suggest that miR-2, as well as MARCKS, might be therapeutic targets for treatment of respiratory diseases characterized by mucus hypersecretion.

\section{Acknowledgements}

Supported by Grant R37 HL36982 from NIH.

\section{REFERENCES}

[1] M. C. Rose and J. A. Voynow "Respiratory Tract Mucin Genes and Mucin Glycoproteins in Health and Disease," Physiological Reviews, Vol. 86, No. 1, 2006, pp. 245278. doi:10.1152/physrev.00010.2005

[2] P. Thai, A. Loukoianov, S. Wachi and R. Wu, "Regulation of Airway Mucin Gene Expression," Annual Review of Physiology, Vol. 70, 2008, pp. 405-429. doi:10.1146/annurev.physiol.70.113006.100441

[3] Y. Li, L. D. Martin, G. Spizz and K. B. Adler, "MARCKS Protein Is a Key Molecule Regulating Mucin Secretion by Human Airway Epithelial Cells in Vitro," Journal of Biological Chemistry, Vol. 276, No. 44, 2001, pp. 4098240990. doi:10.1074/jbc.M105614200 
[4] J. A. Park, A. L. Crews, W. R. Lampe, S. Fang, J. Park and K. B. Adler, "Protein Kinase C Delta Regulates Airway Mucin Secretion via Phosphorylation of MARCKS Protein," American Journal of Pathology, Vol. 171, No. 6, 2007, pp. 1822-1830. doi:10.2353/ajpath.2007.070318

[5] J. Park, S. Fang, A. L. Crews, K. W. Lin and K. B. Adler, "MARCKS Regulation of Mucin Secretion by Airway Epithelium in Vitro: Interaction with Chaperones," American Journal of Respiratory Cell and Molecular Biology, Vol. 39, No. 1, 2008 pp. 68-76. doi:10.1165/rcmb.2007-01390C

[6] M. Singer, L. D. Martin, B. B. Vargaftig, J. Park, A. D. Gruber, Y. Li, et al., "A MARCKS-Related Peptide Blocks Mucus Hypersecretion in a Mouse Model of Asthma," Nature Medicine, Vol. 10, No. 2, 2004, pp. 193-196. doi: $10.1038 / \mathrm{nm} 983$

[7] A. Agrawal, S. Rengarajan, K. B. Adler, A. Ram, B. Ghosh, M. Fahim, et al., "Inhibition of Mucin Secretion with MARCKS-Related Peptide Improves Airway Obstruction in a Mouse Model of Asthma," Journal of Applied Physiology, Vol. 102, No. 1, 2007, pp. 399-405. doi:10.1152/japplphysiol.00630.2006

[8] A. M. Cheng, M. W. Byrom, J. Shelton and L. P. Ford, "Antisense Inhibition of Human miRNAs and Indications for an Involvement of miRNA in Cell Growth and Apoptosis," Nucleic Acids Research, Vol. 33, No. 4, 2005, pp. 1290-1297. doi:10.1093/nar/gki200

[9] C. Z. Chen, L. Li, H. F. Lodish and D. P. Bartel, "MicroRNAs Modulate Hematopoietic Lineage Differentiation," Science, Vol. 303, No. 5654, 2004, pp. 83-86. doi:10.1126/science. 1091903

[10] R. Madhyastha, H. Madhyastha, Y. Nakajima, S. Omura and M. Maruyama, "MicroRNA Signature in Diabetic Wound Healing: Promotive Role of miR-21 in Fibroblast Migration," International Wound Journal, Vol. 9, No. 4, 2012, pp. 355-361. doi:10.1111/j.1742-481X.2011.00890.x

[11] L. Poliseno, A. Tuccoli, L. Mariani, M. Evangelista, L. Citti, K. Woods, et al., "MicroRNAs Modulate the Angiogenic Properties of HUVECs," Blood, Vol. 108, No. 9, 2006, pp. 3068-3071. doi:10.1182/blood-2006-01-012369

[12] P. F. Vaughan, J. H. Walker and C. Peers, "The Regulation of Neurotransmitter Secretion by Protein Kinase C," Molecular Neurobiology, Vol. 18, No. 2, 1998, pp. 125-155. doi:10.1007/BF02914269

[13] Y. Lee, C. Ahn, J. Han, H. Choi, J. Kim, J. Yim, et al., "The Nuclear RNase III Drosha Initiates microRNA Processing," Nature, Vol. 425, No. 425, 2003, pp. 415-419. doi:10.1038/nature01957

[14] P. Xu, M. Guo, B. A. Hay, "MicroRNAs and the Regulation of Cell Death," Trends in Genetics, Vol. 20, No. 12, 2004, pp. 617-624. doi:10.1016/j.tig.2004.09.010

[15] E. Tili, C. M. Croce and J. J. Michaille, "miR-155: On the Crosstalk between Inflammation and Cancer," International Reviews of Immunology, Vol. 28, No. 5, 2009. pp. 264-284. doi:10.1080/08830180903093796

[16] M. Weber, M. B. Baker, J. P. Moore and C. D. Searles, "MiR-21 Is Induced in Endothelial Cells by Shear Stress and Modulates Apoptosis and eNOS Activity," Bio- chemical and Biophysical Research Communications, Vol. 393, No. 4, 2010, pp. 643-648. doi:10.1016/j.bbrc.2010.02.045

[17] C. Sabatel, L. Malvaux, N. Bovy, C. Deroanne, V. Lambert, M. L. Gonzalez, et al., "MicroRNA-21 Exhibits Antiangiogenic Function by Targeting RhoB Expression in Endothelial Cells," PLoS One, Vol. 6, No. 2, 2011, p. e16979. doi:10.1371/journal.pone.0016979

[18] C. K. Sen and S. Roy, "MicroRNA 21 in Tissue Injury and Inflammation," Cardiovascular Research, Vol. 96, No. 2, 2012, pp. 230-233. doi:10.1093/cvr/cvs222

[19] J. P. Thiery, "Epithelial-Mesenchymal Transitions in Development and Pathologies," Current Opinion in Cell Biology, Vol. 15, No. 6, 2003, pp. 740-746. doi:10.1016/j.ceb.2003.10.006

[20] T. Li, D. Li, J. Sha, P. Sun and Y. Huang, "MicroRNA-21 Directly Targets MARCKS and Promotes Apoptosis Resistance and Invasion in Prostate Cancer Cells," Biochemical and Biophysical Research Communications, Vol. 383, No. 3, 2009, pp. 280-285. doi:10.1016/j.bbrc.2009.03.077

[21] T. M. Krunkosky, B. M. Fischer, L. D. Martin, N. Jones, N. J. Akley and K. B. Adler, "Effects of TNF-Alpha on Expression of ICAM-1 in Human Airway Epithelial Cells in Vitro. Signaling Pathways Controlling Surface and Gene Expression," American Journal of Respiratory Cell and Molecular Biology, Vol. 22, No. 6, 2000, pp. 685692. doi:10.1165/ajrcmb.22.6.3925

[22] J. R. Yankaskas, J. E. Haizlip, M. Conrad, D. Koval, E. Lazarowski, A. M. Paradiso, et al., "Papilloma Virus Immortalized Tracheal Epithelial Cells Retain a WellDifferentiated Phenotype," American Journal of Physiol$o g y$, Vol. 264, No. 5, 1993, pp. C1219-C1230.

[23] T. M. Krunkosky, B. M. Fischer, N. J. Akley and K. B. Adler, "Tumor Necrosis Factor Alpha (TNF Alpha)-Induced ICAM-1 Surface Expression in Airway Epithelial Cells in Vitro: Possible Signal Transduction Mechanisms," Annals of the New York Academy Sciences, Vol. 796, 1996, pp. 30-37. doi:10.1111/j.1749-6632.1996.tb32564.x

[24] H. Kai, K. Yoshitake, A. Hisatsune, T. Kido, Y. Isohama, K. Takahama, et al., "Dexamethasone Suppresses Mucus Production and MUC-2 and MUC-5AC Gene Expression by NCI-H292 Cells," American Journal of Physiology, Vol. 271, No. 3, 1996, pp. L484-L488.

[25] J. Milosevic, K. Pandit, M. Magister, E. Rabinovich, D. C. Ellwanger, G. Yu, et al., "Profibrotic Role of miR-154 in Pulmonary Fibrosis," American Journal of Respiratory Cell and Molecular Biology, Vol. 47, No. 6, 2012, pp. 879-887. doi:10.1165/rcmb.2011-0377OC

[26] H. Lin, D. M. Carlson, J. A. St George, C. G. Plopper and R. Wu, "An ELISA Method for the Quantitation of Tracheal Mucins from Human and Nonhuman Primates," American Journal of Respiratory Cell and Molecular Biology, Vol. 1, No. 1, 1989, pp. 41-48. doi:10.1165/ajrcmb/1.1.41

[27] T. D. Green, A. L. Crews, J. Park, S. Fang and K. B. Adler, "Regulation of Mucin Secretion and Inflammation in Asthma: A Role for MARCKS Protein?" Biochimica et 
Biophysica Acta, Vol. 1810, No. 11, 2011, pp. 11101113. doi:10.1016/j.bbagen.2011.01.009

[28] Y. X. Zeng, K. Somasundaram and W. S. El-Deiry, “AP2 Inhibits Cancer Cell Growth and Activates p21WAF1/ CIP1 Expression," Nature Genetics, Vol. 15, No. 1, 1997 , pp. 78-82. doi:10.1038/ng0197-78

[29] M. Hulsmans, D. De Keyzer and P. Holvoet, "MicroRNAs Regulating Oxidative Stress and Inflammation in Relation to Obesity and Atherosclerosis," FASEB Journal, Vol. 25, No. 8, 2011, pp. 2515-2527. doi:10.1096/fj.11-181149

[30] D. Warburton, W. Shi and B. Xu, "TGF-Beta-Smad3 Signaling in Emphysema and Pulmonary Fibrosis: An Epigenetic Aberration of Normal Development?" American Journal of Physiology-Lung Cellular and Molecular Physiology, 2012.

[31] K. W. Lin, S. Fang, J. Park, A. L. Crews and K. B. Adler, "MARCKS and Related Chaperones Bind to Unconventional Myosin V Isoforms in Airway Epithelial Cells," American Journal of Respiratory Cell and Molecular Bi- ology, Vol. 43, No. 2, pp. 131-136. doi:10.1165/rcmb.2010-0016RC

[32] W. M. Foster, K. B. Adler, A. L. Crews, E. N. Potts, B. M. Fischer and J. A. Voynow, "MARCKS-Related Peptide Modulates in Vivo the Secretion of Airway Muc5ac," American Journal of Physiology - Lung Cellular and Molecular Physiology, Vol. 299, No. 3, 2010, pp. L345L352. doi:10.1152/ajplung.00067.2010

[33] J. D. Miller, S. M. Lankford, K. B. Adler and A. R. Brody, "Mesenchymal Stem Cells Require MARCKS Protein for Directed Chemotaxis in Vitro," American Journal of Respiratory Cell and Molecular Biology, Vol. 43, No. 3, 2010, pp. 253-258. doi:10.1165/rcmb.2010-0015RC

[34] R. E. Eckert, L. E. Neuder, J. Park, K. B. Adler and S. L. Jones, "Myristoylated Alanine-Rich C-Kinase Substrate (MARCKS) Protein Regulation of Human Neutrophil Migration," American Journal of Respiratory Cell and Molecular Biology, Vol. 42, No. 5, 2010, pp. 586-594. doi:10.1165/rcmb.2008-0394OC 